Received January 6, 2020

Revised March 14, 2020

Accepted March 20, 2020

\author{
Corresponding author \\ Sang-Hwan Do, M.D., Ph.D. \\ Department of Anesthesiology and \\ Pain Medicine, Seoul National \\ University Bundang Hospital, 82 \\ Gumi-ro 173beon-gil, Bundang-gu, \\ Seongnam 13620, Korea \\ Tel: 82-31-787-7501 \\ Fax: 82-31-787-4063 \\ E-mail: shdo@snu.ac.kr
}

\section{Effects of tranexamic acid on the activity of glutamate transporter EAAT3}

\author{
Hyun-Jung Shin ${ }^{1}$, Soo-Young Lee ${ }^{2}$, Hyo-Seok Na', \\ Bon-Wook Koo', Jung-Hee Ryu', and Sang-Hwan Do'
}

${ }^{1}$ Department of Anesthesiology and Pain Medicine, Seoul National University Bundang Hospital, Seongnam, ${ }^{2}$ Department of Anesthesiology and Pain Medicine, ThanQ Seoul Thyroid-Head \& Neck Surgery Center, Seoul, Korea

\begin{abstract}
Background: Tranexamic acid (TXA) is the most widely used hemostatic agent in surgical patients. However, when used in a high dose, it could cause a seizure in the postoperative period. The exact effector mechanism behind the seizure triggering remains unknown. Therefore, the authors investigated the effects of TXA on the activity of glutamate transporter type 3 (excitatory amino acid transporter 3; EAAT3), which is the main neuronal glutamate transporter type.

Methods: EAAT3 was expressed in Xenopus laevis oocytes through mRNA injection. Oocytes were incubated with diluted tranexamic acid for $72 \mathrm{~h}$. Two-electrode voltage clamping was used to measure membrane currents before, during, and after applying $30 \mu \mathrm{M}$ L-glutamate. Responses were quantified by integrating the current traces and reported in microcoulombs $(\mu \mathrm{C})$. Results were presented as mean \pm SEM.
\end{abstract}

Results: TXA (30 to 1,000 $\mu \mathrm{M}$ ) significantly decreased EAAT3 activity. Our kinetic study showed that $\mathrm{V}_{\max }$ was significantly decreased in the TXA group compared with the control group (1.1 \pm 0.1 vs. $1.4 \pm 0.1 \mu \mathrm{C}, \mathrm{n}=18-23, \mathrm{P}=0.043$ ), but the $\mathrm{K}_{\mathrm{m}}$ did not significantly change $(12.7 \pm 3.9 \mu \mathrm{M}$ for TXA vs. $12.8 \pm 3.8$ for control, $n=18-23, P=0.986)$.

Conclusions: Our results suggest that TXA attenuates EAAT3 activity, which may explain its proconvulsant effect.

Keywords: Electrophysiology; Excitatory amino acid transporter 3; Glutamate plasma membrane transport proteins; Tranexamic acid; Xenopus laevis.

\section{INTRODUCTION}

Tranexamic acid (TXA) is the most widely used hemostatic agent in surgical patients, and it is known to induce hemostasis by binding to the lysine binding site of plasminogen, which in turn decreases plasmin activity and lowers fibrin degradation. However, the TXA application may have side effects in the central nervous system (CNS), such as inducing seizures $[1,2]$. Seizures, caused by an intraoperative use of TXA, not only delay recovery but also have an adverse impact on the patient's outcome. It has been previously reported that the TXA-induced seizure effector mechanism involves inhibitory neurotransmitter inhibition through gamma-aminobutyric acid (GABA) or glycine receptors [3]. However, unlike glial excitatory amino acid transporters (EAAT1 and EAAT2), which usually regulate excitatory neurotransmitters, EAAT3, a major neuronal EAAT, exists both in inhibitory and excitatory neurons, thereby regulating GABAergic neurotransmission

This is an Open Access article distributed under the terms of the Creative Commons Attribution Non-Commercial License (http://creativecommons.org/licenses/by-nc/4.0) which permits unrestricted non-commercial use, distribution, and reproduction in any medium, provided the original work is properly cited.

Copyright (C) the Korean Society of Anesthesiologists, 2020 
through precursor glutamate uptake [4].

EAATs, also called glutamate transporters, are membrane proteins that are present in neurons and glial cells in the CNS [5]. Glutamate is a major excitatory neurotransmitter with neurotoxic effect at high extracellular concentrations. EAATs play a crucial role in transporting glutamates from the extracellular space to inside the cell. EAAT dysfunction leads to an extracellular glutamate accumulation, thereby causing glutamate-induced neural damage or excitotoxicity, associated with ischemic brain injury pathophysiology and neurodegenerative diseases, such as amyotrophic lateral sclerosis [6-8]. To date, there are five subtypes of EAATs. EAAT3 is the major EAAT and is expressed in neurons [5].

This study aims at investigating the impact of TXA on EAAT3 activity by measuring TXA-induced membrane potential changes using a two-electrode voltage clamp in a Xenopus oocyte expression system, and to examine the TXA effect patterns on EAAT3 through a kinetic study.

\section{MATERIALS AND METHODS}

\section{Xenopus oocyte preparation and EAAT3 expression studies}

Fig. 1 shows a schematic diagram of the process of EAAT3 expression. Xenopus laevis, a research model frog, was managed in an independent water tank with twice-weekly feedings. To obtain oocytes, $0.2 \%$ 3-aminobenzoic ethyl ester (Sigma, USA) was added to $500 \mathrm{ml}$ of water, in which the animal was subsequently immersed for $30 \mathrm{~min}$, and once its response to the painful stimuli was lost, the animal was placed on an ice bath in a supine position. A 0.5-1-cm incision was made in the lower lateral abdominal wall to obtain a part of the ovarian tissue, which was immediately placed into a modified Barth's solution ( $\mathrm{NaCl} 88 \mathrm{mM}$, KCl $1 \mathrm{mM}, \mathrm{NaHCO}_{3} 2.4 \mathrm{mM}, \mathrm{CaCl}_{2} 0.41 \mathrm{mM}$, $\mathrm{MgSO}_{4} 0.82 \mathrm{mM}, \mathrm{Ca}\left(\mathrm{No}_{3}\right)_{2} 0.3 \mathrm{mM}$, gentamicin $0.1 \mathrm{mM}$, HEPES $15 \mathrm{mM}, \mathrm{pH}$ 7.6). After removing the follicular layer, the tissue was placed into an OR-2 solution $(\mathrm{NaCl} 82.5 \mathrm{mM}$, $\mathrm{KCl} 2 \mathrm{mM}, \mathrm{MgCl}_{2} 1 \mathrm{mM}$, HEPES $5 \mathrm{mM}$, collagenase type Ia $0.1 \%, \mathrm{pH} 7.5$ ), mildly shaken for two hours, then incubated in modified Barth's solution for storage at $16^{\circ} \mathrm{C}$.

The EAAT3 cDNA was provided by Dr. Mattias A. Hediger (Brigham and Women's Hospital, Harvard Institute of Medicine, USA), and it was subcloned into a commercial vector (Bluescript-SKm). After a restriction endonuclease (Not I) treatment, mRNA was prepared using a commercial kit (Ambion, USA). The mRNA quantitative analysis was performed using a spectrophotometer. The obtained mRNA (concentration: $30 \mathrm{ng} / 30 \mathrm{nl}$ ) was injected into the oocyte cytoplasm using an automatic injector (Drummond Nanoject, Drummond Scientific Co., USA).

\section{Electrophysiological measurements}

The experiment was conducted at $21-23^{\circ} \mathrm{C}$, considered as room temperature. A single defolliculated oocyte was placed in the recording chamber of a 2-electrode voltage clamp (OC725-A, Warner Corporation, USA), and while perfusing with Tyrode solution (150 mM NaCl, $5 \mathrm{mM} \mathrm{KCl,} 2 \mathrm{mM} \mathrm{CaCl}_{2}$, $1 \mathrm{mM} \mathrm{MgSO}_{4}, 10 \mathrm{mM}$ dextrose, $10 \mathrm{mM}$ HEPES, pH 7.5), the oocyte was pricked at the sides with the microelectrodes connected to the voltage clamp to measure the membrane potential. The membrane potential value obtained from the voltage clamp was processed with the DAS-8A conversion board (Keithley-Metrabyte, USA) and analyzed using the Ooclamp software. All measurements were conducted at a holding potential of $-70 \mathrm{mV}$. Oocytes not showing a stable holding current of less than $1 \mathrm{~mA}$ were excluded from the analysis. The oocyte was then superfused with Tyrode solution-diluted L-glutamate for $20 \mathrm{~s}$ at $3 \mathrm{ml} / \mathrm{min}$, and the membrane potentials were measured at $125 \mathrm{~Hz}$ for one minute. We integrated the bell-shaped current trace to quantify the response and describe the value as microCoulombs $(\mu \mathrm{C})$, which equates to the total amount of transported glutamate. Each experiment was performed by using oocytes obtained from at least three different Xenopus frogs.

\section{Injection of various chemicals}

To examine the effects of TXA on EAAT3 activity, we ex-

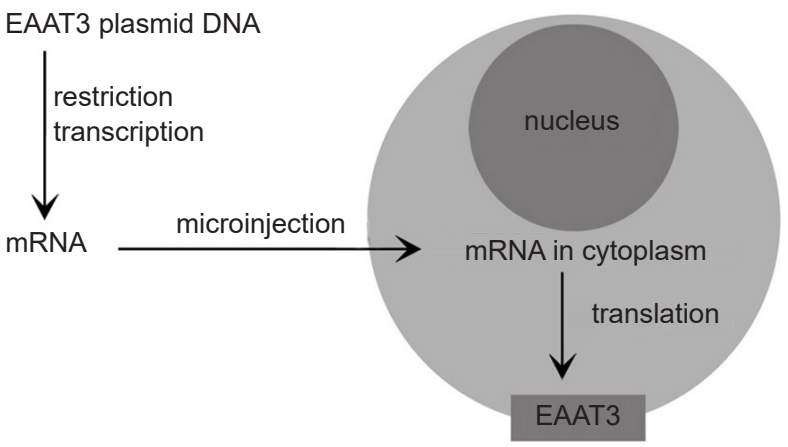

Fig. 1. The EAAT3 expression process. EAAT3: excitatory amino acid transporter 3. 
posed oocytes to various TXA concentrations diluted in a modified Barth solution $(3,10,30,100,300,1,000 \mu \mathrm{M})$ for $72 \mathrm{~h}$ and measured membrane potential changes after injecting an agonist (L-glutamate $30 \mu \mathrm{M}$ ). The control group oocytes were incubated in a modified, non-TXA-containing Barth solution for $72 \mathrm{~h}$ before the response measurement. In this experiment, we used the agonist L-glutamate to induce a glutamate transporter current through EAAT3. In our previous study, we established that the EAAT3 response-triggering L-glutamate median effective concentration $\left(\mathrm{EC}_{50}\right)$ is $27.2 \mu \mathrm{M}$ [9], we thus used $30 \mu \mathrm{M}$ of L-glutamate in this study. After computing responses at each TXA concentration, we performed a kinetic study to compute $\mathrm{K}_{\mathrm{m}}$ and $\mathrm{V}_{\max }$ by measuring response values in the control group and the experimental group upon exposure to a TXA concentration close to the half-maximal inhibitory concentration $\left(\mathrm{IC}_{50}\right)$ using five different L-glutamate concentrations $(3,10,30,100,300 \mu \mathrm{M})$.

\section{Data analysis}

The response values were presented as mean \pm SEM. As the response values commonly vary depending on the oocyte batch, we obtained normalized data by dividing the response values by the average value of the control group in each batch for the dose-response study. Between-group differences were analyzed with student's $t$-test or one-way analysis of variance (ANOVA). Post-hoc comparison was performed with Bonferroni correction or Student-Newman-Keuls correction. Statistical differences were considered significant for $\mathrm{P}$ values $<0.05$.

\section{RESULTS}

Oocytes injected with EAAT3 mRNA showed inward currents in response to the application of L-glutamate. In contrast to that, no membrane current changes were observed in oocytes that were not injected with EAAT3 mRNA. No membrane potential changes were observed when EAAT3 mRNA-not injected oocytes were exposed to TXA. Accordingly, all subsequent experiments were conducted only with oocytes injected with EAAT3 mRNA.

Exposing the oocytes to various TXA concentrations showed that TXA decreased EAAT3 activity in a dose-dependent manner (Fig. 2). In the kinetic study, we used the lowest TXA concentration of $30 \mu \mathrm{M}$ that significantly decreased EAAT3 activity.
Compared to the control group, the TXA exposure group $(30 \mu \mathrm{M})$ showed a significant reduction in the response to $10,30,100$, and $300 \mu \mathrm{M}$ L-glutamate except $3 \mu \mathrm{M}$ L-glutamate (Fig. 3). A further analysis of the data demonstrated that TXA significantly decreased $V_{\max }(1.1 \pm 0.1 \mu \mathrm{C}$ for TXA vs. $1.4 \pm 0.1 \mu \mathrm{C}$ for control; $\mathrm{n}=18-23$ in each group, $\mathrm{P}=$ 0.043). However, TXA did not cause a significant change in $\mathrm{K}_{\mathrm{m}}$ value for EAAT3 in response to L-glutamate $12.7 \pm 3.9$ $\mu \mathrm{M}$ for TXA vs. $12.8 \pm 3.8 \mu \mathrm{M}$ for control; $\mathrm{n}=18-23$ in each group, $\mathrm{P}=0.986$ ).

\section{DISCUSSION}

As an antifibrinolytic agent, TXA effectively promotes hemostasis in surgical patients, but there have been concerns about its main adverse effect, namely postoperative seizure. Such an effect has been frequently reported in car-

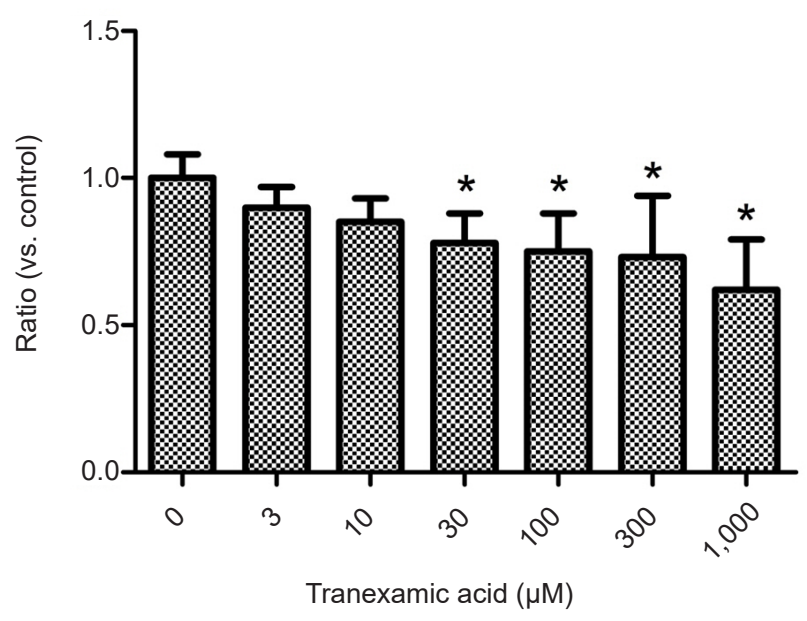

Fig. 2. Changes in EAAT3 activity relative to tranexamic acid exposure level. EAAT3: excitatory amino acid transporter 3. *P $<0.05$ compared with the control group (tranexamic acid concentration $0 \mu \mathrm{M}$ ).

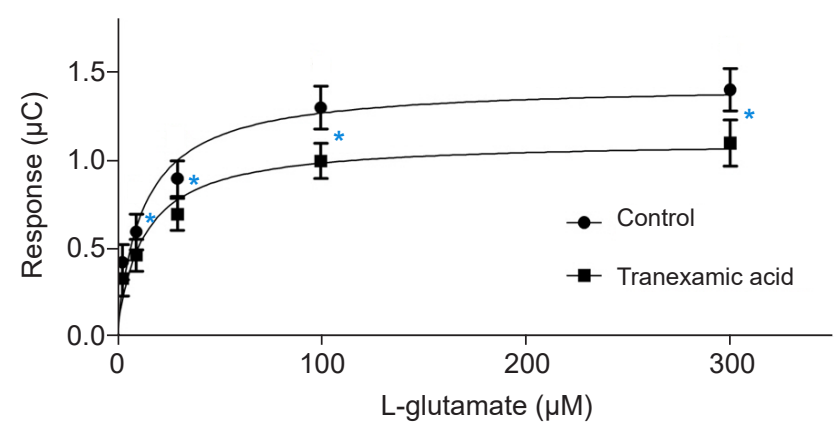

Fig. 3. EAAT3 dose-response curve of for L-glutamate relative to tranexamic acid presence. EAAT3: excitatory amino acid transporter 3. ${ }^{\star P}<0.05$ compared with control group (tranexamic acid concentration $0 \mu \mathrm{M})$. 
diac surgeries when a high TXA dose was used [10]. TXA-induced seizures occur within several hours of transferring the patient from the operating room to an intensive care unit, a period characterized by a rapid decline of anesthetics with an anticonvulsant effect and high TXA concentration [11]. A recently published meta-analysis of 28 randomized controlled studies reported a high-risk ratio (6.67) of postoperative seizure for using TXA during coronary artery bypass grafting [12].

No theory has been established for the CNS mechanism underlying TXA-induced seizures. It has been reported that TXA has an inhibitory effect on inhibitory neurotransmitter receptors GABA and glycine receptors, but its effect on the excitatory glutamate neurotransmission has not been reported yet. Particularly, EAAT3, a main glutamate neurotransmission-regulating EAAT, plays an important role in maintaining GABA neurotransmission towards neurons by providing the glutamate needed for GABA synthesis $[4,13]$. Therefore, studies on the effect of TXA on EAAT3 activity would provide a key to understanding the effector mechanism of TXA-induced seizures.

Lecker et al. [14] established peak TXA concentrations at $1.9 \pm 0.4 \mathrm{mM}$ in the serum and $220.8 \pm 116.7 \mu \mathrm{M}$ in the cerebrospinal fluid in patients undergoing heart surgery using a cardiopulmonary bypass machine. Furthermore, in the same study, the half-maximal inhibitory concentration $\left(\mathrm{IC}_{50}\right)$, measuring the TXA inhibition of glycine receptors, was $1.1 \mathrm{mM}$.

In this study, TXA significantly decreased EAAT3 activity at concentrations of 30, 100, 300, and 1,000 $\mu \mathrm{M}$. Decreased EAAT3 activity lowers glutamate uptake into neurons and thus increases extracellular glutamate concentration, which can explain the onset of seizures. In our previous study, we observed that etomidate and estrogen (17- $\beta$-estradiol), which have a proconvulsant effect, also decreased EAAT3 activity $[15,16]$. Moreover, the results of the kinetic study shed light on how TXA alters EAAT3 activity. In other words, considering that TXA significantly reduced $\mathrm{V}_{\max }$ but did not significantly alter $K_{m}$, it is appropriate to assume that TXA causes dynamic changes, such as increasing the number of available EAAT3 or its turnover rate, in the neuronal cell membrane as opposed to changing the affinity of EAAT3 for glutamate.

The TXA-induced CNS hyperexcitation seems to be attributable to the so-called "disinhibition" that reduces neurotransmission [17]. Glycine receptors and $\mathrm{GABA}_{\mathrm{A}}$ receptors are some of the major inhibitory neurotransmission systems in the CNS. According to Furtmüller et al. [18], while TXA does inhibit $\mathrm{GABA}_{\mathrm{A}}$ receptors, its $\mathrm{IC}_{50}$ is quite high, at $7 \mathrm{mM}$. That is, although we could not calculate $\mathrm{IC}_{50}$ in the present study due to the atypical pattern of EAAT3 activity across varying TXA concentrations, the result that EAAT3 activity was significantly decreased at concentrations of $30 \mu \mathrm{M}$ or higher suggests that EAAT3 had significant responses to markedly lower TXA concentrations compared to glycine or $\mathrm{GABA}_{\mathrm{A}}$ receptors. However, a comprehensive comparison is difficult due to the differences in the experimental methods.

There are several methods of measuring glutamate transporter activity, and we chose electrophysiological measurement using a 2-electrode voltage clamp in the present study. For this method, Xenopus oocytes from Xenopus laevis frogs are essential. Xenopus oocytes are widely utilized in experiments using a voltage clamp, as they do not contain endogenous receptors other than lysophosphatidate receptors, and receptor proteins can be expressed on the cell membrane within a few days of injecting the DNA or RNA of various receptors into the nucleus or cytoplasm.

In this study, we observed that TXA attenuates EAAT3 activity but could not identify its mechanism. It is possible that TXA can affect EAAT3 activity through its impact on enzymes that regulate intracellular signaling, such as protein kinase C (PKC) or phosphatidylinositol 3-kinase (PI3K). We also observed in our previous studies that various anesthetics, hormones, alcohol, caffeine, and nicotine alter glutamate transporter activity through the mediation of PKC or PI3K [19-22]. However, we could not additionally study PKC or PI3K in the present study due to inadequate study conditions. Furthermore, we used normalized data obtained by dividing each response value by the average of the control for each oocyte batch instead of the raw data when analyzing the results of the dose-response experiment. This is a common method in electrophysiological experiments using the Xenopus oocyte expression system, and we have used this method in our previous studies as well $[9,12,17-20,23,24]$.

In conclusion, we used the Xenopus oocyte expression system and observed that TXA decreases the activity of glutamate transporter, EAAT3, presumably by increasing the number of available EAAT3 or its turnover rate as opposed to altering its affinity for glutamate. Additional studies are needed to examine the underlying mechanism.

\section{ACKNOWLEDGEMENTS}


This experiment was supported by a grant (no. 02-2014011) from the Research Fund of Seoul National University Bundang Hospital, Korea.

\section{SUPPLEMENTARY MATERIALS}

Supplementary data containing Korean version of this article is available at https://doi.org/10.17085/apm.20004.

\section{CONFLICTS OF INTEREST}

No potential conflict of interest relevant to this article was reported.

\section{AUTHOR CONTRIBUTIONS}

Conceptualization: Hyun-Jung Shin, Sang-Hwan Do. Data aquisition: Soo-Young Lee, Bon-Wook Koo. Formal analysis: Hyo-Seok Na, Jung-Hee Ryu. Funding: SangHwan Do. Supervision: Sang-Hwan Do. Writing-original draft: Bon-Wook Koo. Writing-review \& editing: Hyun-Jung Shin, Sang-Hwan Do.

\section{ORCID}

Hyun-Jung Shin, https://orcid.org/0000-0003-0991-7061 Soo-Young Lee, https://orcid.org/0000-0002-2053-0055 Hyo-Seok Na, https://orcid.org/0000-0003-0986-3243 Bon-Wook Koo, https://orcid.org/0000-0001-5311-8115 Jung-Hee Ryu, https://orcid.org/0000-0001-9331-5658 Sang-Hwan Do, https://orcid.org/0000-0001-5452-4166

\section{REFERENCES}

1. Kalavrouziotis D, Voisine P, Mohammadi S, Dionne S, Dagenais F. High-dose tranexamic acid is an independent predictor of early seizure after cardiopulmonary bypass. Ann Thorac Surg 2012; 93: 148-54.

2. Merriman B, Mayson K, Sawka A, Akagami R, Flexman AM. Postoperative seizure in a neurosurgical patient: should tranexamic acid be on the differential? Can J Anaesth 2013; 60: 506-7.

3. Kratzer S, Irl H, Mattusch C, Bürge M, Kurz J, Kochs E, et al. Tranexamic acid impairs $\gamma$-aminobutyric acid receptor type A-mediated synaptic transmission in the murine amygdala: a potential mechanism for drug-induced seizures? Anesthesiol- ogy 2014; 120: 639-49.

4. Sepkuty JP, Cohen AS, Eccles C, Rafiq A, Behar K, Ganel R, et al. A neuronal glutamate transporter contributes to neurotransmitter GABA synthesis and epilepsy. J Neurosci 2002; 22: 63729.

5. Danbolt NC. Glutamate uptake. Prog Neurobiol 2001; 65: 1 105.

6. Beart PM, O'Shea RD. Transporters for L-glutamate: an update on their molecular pharmacology and pathological involvement. Br J Pharmacol 2007; 150: 5-17.

7. Maragakis NJ, Rothstein JD. Glutamate transporters in neurologic disease. Arch Neurol 2001; 58: 365-70.

8. Sheldon AL, Robinson MB. The role of glutamate transporters in neurodegenerative diseases and potential opportunities for intervention. Neurochem Int 2007; 51: 333-55.

9. Do SH, Kamatchi GL, Washington JM, Zuo Z. Effects of volatile anesthetics on glutamate transporter, excitatory amino acid transporter type 3: the role of protein kinase C. Anesthesiology 2002; 96: 1492-7.

10. Guo J, Gao X, Ma Y, Lv H, Hu W, Zhang S, et al. Different dose regimes and administration methods of tranexamic acid in cardiac surgery: a meta-analysis of randomized trials. BMC Anesthesiol 2019; 19: 129.

11. Manji RA, Grocott HP, Leake J, Ariano RE, Manji JS, Menkis AH, et al. Seizures following cardiac surgery: the impact of tranexamic acid and other risk factors. Can J Anaesth 2012; 59: 6-13.

12. Zhang Y, Bai Y, Chen M, Zhou Y, Yu X, Zhou H, et al. The safety and efficiency of intravenous administration of tranexamic acid in coronary artery bypass grafting (CABG): a meta-analysis of 28 randomized controlled trials. BMC Anesthesiol 2019; 19: 104.

13. Mathews GC, Diamond JS. Neuronal glutamate uptake contributes to GABA synthesis and inhibitory synaptic strength. J Neurosci 2003; 23: 2040-8.

14. Lecker I, Wang DS, Romaschin AD, Peterson M, Mazer CD, Orser BA. Tranexamic acid concentrations associated with human seizures inhibit glycine receptors. J Clin Invest 2012; 122: 4654-66.

15. Na HS, Park HP, Kim CS, Do SH, Zuo Z, Kim CS. 17 $\beta$-Estradiol attenuates the activity of the glutamate transporter type 3 expressed in Xenopus oocytes. Eur J Pharmacol 2012; 676: 20-5.

16. Yun JY, Kim JH, Kim HK, Lim YJ, Do SH, Zuo Z. Effects of intravenous anesthetics on the activity of glutamate transporter EAAT3 expressed in Xenopus oocytes: evidence for protein kinase C involvement. Eur J Pharmacol 2006; 531: 133-9.

17. Lecker I, Wang DS, Whissell PD, Avramescu S, Mazer CD, Orser 
BA. Tranexamic acid-associated seizures: causes and treatment. Ann Neurol 2016; 79: 18-26.

18. Furtmüller R, Schlag MG, Berger M, Hopf R, Huck S, Sieghart W, et al. Tranexamic acid, a widely used antifibrinolytic agent, causes convulsions by a gamma-aminobutyric acid(A) receptor antagonistic effect. J Pharmacol Exp Ther 2002; 301: 168-73.

19. Kim JH, Do SH, Kim YL, Zuo Z. Effects of chronic exposure to ethanol on glutamate transporter EAAT3 expressed in Xenopus oocytes: evidence for protein kinase C involvement. Alcohol Clin Exp Res 2005; 29: 2046-52.

20. Kim JH, Lim YJ, Ro YJ, Min SW, Kim CS, Do SH, et al. Effects of ethanol on the rat glutamate excitatory amino acid transporter type 3 expressed in Xenopus oocytes: role of protein kinase $\mathrm{C}$ and phosphatidylinositol 3-kinase. Alcohol Clin Exp Res 2003;
27: 1548-53.

21. Shin HJ, Ryu JH, Kim ST, Zuo Z, Do SH. Caffeine-induced inhibition of the activity of glutamate transporter type 3 expressed in Xenopus oocytes. Toxicol Lett 2013; 217: 143-8.

22. Yoon HJ, Lim YJ, Zuo Z, Hur W, Do SH. Nicotine decreases the activity of glutamate transporter type 3. Toxicol Lett 2014; 225: $147-52$

23. Ryu J, Do SH, Lee N. Remifentanil increases the activity of the glutamate transporter, EAAC1, expressed in Xenopus oocytes. Anesth Pain Med 2008; 3: 264-9.

24. Ryu JH, Kim CS, Do SH, Park HS. Effect of propofol on oxidative stress-attenuated glutamate transporter EAAT4 activity. Anesth Pain Med 2011; 6: 225-30. 